\title{
Mortality from cardiovascular diseases and exposure to inorganic mercury
}

P Boffetta, G Sällsten, M Garcia-Gómez, V Pompe-Kirn, D Zaridze, M Bulbulyan, J-D Caballero, F Ceccarelli, A B Kobal, E Merler

Unit of Environmental Cancer Epidemiology, International Agency for Research on Cancer, 150 Cours Albert-Thomas, 69372 Lyon Cedex 08, Lyon, France

P Boffetta Occupational

Medicine, University of Göteborg, Sweden G Sällsten

Division of Epidemiology, Madrid, Spain

M Garcia-Gómez

National Cancer Registry, Institute of Oncology, Ljubljana, Slovenia

V Pompe-Kirn

Institute of Carcinogenesis, Cancer Research Centre, Moscow, Russia

D Zaridze

M Bulbulyan

Industrial and Occupational Service, Ciudad Real, Spain J-D Caballero

National Health Service, Abbadia San Salvatore, Italy F Ceccarelli

Idrija Mercury Mine, Idrija, Slovenia

A B Kobal

Centre for the Study and Prevention of Cancer, Florence, Italy E Merler

Correspondence to: Dr P Boffetta,

boffetta@iarc.fr

Accepted 9 March 2001
Department of Ministry of Health,

\begin{abstract}
Objective-To study the mortality from cardiovascular and other chronic nonneoplastic diseases after long term exposure to inorganic mercury. Limited information is available on the effect of chronic exposure to mercury on the cardiovascular system.
\end{abstract}

Methods-The mortality was studied among 6784 male and 265 female workers from four mercury mines and mills in Spain, Slovenia, Italy, and the Ukraine. Workers were employed between 1900 and 1990; the follow up period lasted from the 1950 s to the $1990 \mathrm{~s}$. The mortality of the workers was compared with national reference rates.

Results-Among men, there was a slight increase in overall mortality (standardised mortality ratio (SMR) 1.08 , $95 \%$ confidence interval (95\% CI) 1.04 to 1.12$)$. An increased mortality was found from hypertension (SMR 1.46, 95\% CI 1.08 to 1.93), heart diseases other than ischaemic (SMR 1.36, 95\% CI 1.20 to 1.53), pneumoconiosis (SMR 27.1, 95\% CI 23.1 to 31.6), and nephritis and nephrosis (SMR 1.55, $95 \%$ CI 1.13 to 2.06 ). The increase in mortality from cardiovascular diseases was not consistent among countries. Mortality from hypertension and other heart diseases increased with estimated cumulative exposure to mercury; mortality from ischaemic heart disease and cerebrovascular diseases increased with duration of employment, but not with estimated exposure to mercury. Results among women were hampered by few deaths.

Conclusion-Despite limited quantitative data on exposure, possible confounding, and likely misclassification of disease, the study suggests a possible association between employment in mercury mining and refining and risk in some groups of cardiovascular diseases.

(Occup Environ Med 2001;58:461-466)

Keywords: epidemiology; inorganic mercury; mining; cardiovascular diseases

Table 1 Characteristics of cohorts included in the study

\begin{tabular}{|c|c|c|c|c|c|c|}
\hline Country & Mine & $\begin{array}{l}\text { Period of } \\
\text { employment }\end{array}$ & $\begin{array}{l}\text { Period of follow } \\
\text { up }\end{array}$ & $\operatorname{Sex}$ & $\begin{array}{l}\text { Workers } \\
(n)\end{array}$ & Person-years \\
\hline Italy & Abbadia & $1920-1983$ & 1950-1994 & Men & 1059 & 38351 \\
\hline Spain & Almaden & 1897-1994 & 1950-1994 & Men & 3648 & 103728 \\
\hline Slovenia & Idrija & $1950-1990$ & $1950-1995$ & Men & 1589 & 49056 \\
\hline Ukraine & Nikitovka & $1943-1990$ & $1958-1990$ & Men & 488 & 8622 \\
\hline Total & & & & Men & 6784 & 199757 \\
\hline Ukraine & Nikitovka & $1943-1990$ & $1958-1990$ & Women & 265 & 5307 \\
\hline
\end{tabular}

The toxicity of high doses of inorganic mercury on the central nervous and urinary systems have been known for decades. ${ }^{1}$ Few data, however, are available on the health effect of prolonged exposure to low doses, and on the effects on other organs, notably the heart and the blood vessels.

We have recently reported the results on cancer risk among workers exposed to inorganic mercury in four mines and refinery plants in Europe. ${ }^{2}$ We did not detect a consistent increase in cancer risk, with the possible exception of liver cancer. Within the frame of this study, we also assessed the risk of these workers of dying from non-neoplastic diseases, and in particular from cardiovascular diseases: these results form the basis of the present report.

\section{Methods}

The methods of this study have been described in detail previously. ${ }^{2}$ Briefly, the study population comprises workers employed in four mercury mines in Europe (table 1): Abbadia San Salvatore in Italy, Almaden in Spain, Idrija in Slovenia, and Nikitovka in the Ukraine. We selected these mines on the basis of size, production rate, and availability of records on employment and on mortality or cancer incidence. All four national components included men, but women were also employed at the Ukrainian mine. The cohorts from Spain and Slovenia included both miners and millers, whereas the cohorts from the Ukraine and Italy included millers only, as no native mercury was present in these mines. For the purpose of our analysis we selected workers exposed to inorganic mercury while they were employed in a production department and we excluded workers employed only in non-production departments. The employment period started at the 1st year of availability of employment records; the follow up started at the 1st year of availability of mortality records (1958 in the Ukraine, 1950 in the other countries; table 1). The total cohort comprised 6784 men and 265 women exposed to mercury, who contributed 199757 and 5307 person-years of observation, respectively.

We abstracted information for each job held by the workers. In many instances, however, workers rotated periodically among different jobs, and a classification was possible only at the level of department of employment. Most workers were employed in the mine $(23 \%)$, in the mill $(26 \%)$, or in both $(32 \%)$; smaller groups of workers were employed in mercury bottle filling and in the laboratories attached to each mine. For the purpose of this analysis, workers were classified according to the longest 
held department and according to ever employed in the mine and in the mill.

We estimated quantitatively the exposure to inorganic mercury, expressed as $\mu \mathrm{g} / \mathrm{l}$ urinary mercury, in each mine and mill on the basis of urinary and blood biomonitoring data, industrial hygiene measurements, and reconstruction of technological and hygienic conditions in different periods. No biological data were available from the Ukraine. The urinary data from Slovenia, Spain, and Italy consisted of more than 20000 individual measurements, mainly from the 1970s, and onwards, and about 1000 blood measurements were available. The cold vapour atomic absorption technique has been the dominating analytical method for mercury measurement. Individual annual mean values were calculated from the data from Slovenia and Italy and used in the evaluation of the mean exposures for miners and millers for different periods. From Spain we obtained average values for all measurements performed in miners in the 1970s and 1980s, and in millers for the period 1985-6. Assessment of the exposure for earlier periods was based on knowledge of technical and hygiene improvements at the different places as well as results from spot measurements of mercury in air performed mainly in the mills of Slovenia and the Ukraine, and the mine of Slovenia since the mid-1950s. The concentrations estimated for the mines varied from 1500 $\mu \mathrm{g} / 1$ during $1930-60$ in Spain to $100-300 \mu \mathrm{g} / 1$ since 1985 in both Spain and Slovenia. Estimated concentrations in the mills until the 1960s were $500-600 \mu \mathrm{g} / 1$ in Italy, Slovenia, and the Ukraine and $300 \mu \mathrm{g} / 1$ in Spain. They decreased in the $1980 \mathrm{~s}$ to $300 \mu \mathrm{g} / 1$ in the Ukraine and $100-150 \mu \mathrm{g} / \mathrm{l}$ in the other countries. ${ }^{2}$ For each worker, we constructed a cumulative exposure index by summing up the estimates for each year of employment.

As well as inorganic mercury, workers in mines and mills have been exposed to dust that contained free crystalline silica. In the Slovenian mine, dust measurements showed concentrations between 30 and $70 \mathrm{mg} / \mathrm{m}^{3}$ with $10 \%$ to $35 \%$ free silica in the $1960 \mathrm{~s}$, and about $40 \mathrm{mg} / \mathrm{m}^{3}$ in the $1970 \mathrm{~s}^{3}$ Personal dust measurements performed in workers at the Spanish mill in the late 1970 s showed dust concentrations of about $5 \mathrm{mg} / \mathrm{m}^{3}$ (total dust) with a content of about $10 \%$ free silica. Dust concentrations in the mine were likely to be as high as those recorded in Slovenia. Radon and its decay products were present in the mine in Slovenia and in the ore in the Ukraine, although information on radon is lacking for Spain and Italy. There were no indications of exposure to asbestos or diesel engine exhausts at any of the mines.

Workers were followed up for mortality according to different procedures in the various countries. They contributed person-years of observation from beginning of follow up, or of employment, to death, to end of follow up, or for workers lost to follow up, to date of last contact. In each country, the follow up was conducted according to the procedures usually employed in occupational cohort studies. Specifically, in Italy, information on vital status was obtained from the municipality of residence and death certificates were obtained from the municipality of death. In Spain, information was obtained from the mine, the municipality of residence, the census, the National Institute of Statistics and Social Security, and death certificates were obtained from the municipality of death. In the Ukraine, information on vital status and cause of death was obtained from the local Address Bureau. Finally, in Slovenia, the medical records of the mine and the records of the National Population Register were used to collect information on vital status, and death certificates were obtained from the municipality of death.

Causes of deaths were abstracted from death certificates and coded according to the revision of the international classification of diseases (ICD) in use at the time of the death. Codes were subsequently translated into codes of the 9 th revision (ICD-9). We derived the expected number of deaths from the national rates specific for sex, age, and calendar period. For Italy, Slovenia, and Spain we used the rates available in the World Health Organisation (WHO) mortality database. For Italy and Spain, the available rates covered the whole study period. For Slovenia, the WHO database comprises rates from 1985; for previous years, we applied a linear extrapolation; similarly, for the Ukraine, we used mortalities for the period 1971-90 and applied a linear extrapolation for the preceding period. No reference rates were available for selected causes of death in the Ukrainian cohort. We therefore calculated standardised mortality ratios (SMRs) based on the other three cohorts. In the analyses based on internal comparisons, however, personyears and deaths from the Ukrainian cohort were used.

We calculated SMRs as the ratio of observed and expected deaths. Ninety five per cent confidence intervals (95\% CIs) of SMRs were based on the Poisson distribution of observed deaths. We also conducted an internal comparison of rates based on multivariate Poisson regression. ${ }^{4}$ Regression models included terms for age, country, calendar period, time since first exposure, and exposure estimates.

\section{Results}

We ascertained the vital status of $92 \%$ of the workers in Spain, 83\% in the Ukraine, and $100 \%$ in Italy and Slovenia (overall rate of loss to follow up was $6 \%$ ). At the end of the follow up, 3623 male workers were alive (53\%) and 2749 had died $(41 \%)$.

Among male workers, the SMR for all causes was 1.08 (95\% CI 1.04 to 1.12$)$ : an increase was present among workers from Slovenia (SMR 1.18, 95\% CI 1.09 to 1.28) and Spain (SMR 1.14, 95\% CI 1.09 to 1.20 ), whereas workers from the Ukraine (SMR 0.90, 95\% CI 0.73 to 1.09 ) and Italy (SMR $0.90,95 \%$ CI 0.83 to 0.98 ) experienced fewer deaths than expected. The cause of death was unknown for 118 male workers (4.3\%): 99 of them were 
Table 2 Mortality from selected causes among men

\begin{tabular}{|c|c|c|c|c|c|}
\hline Cause of death (ICD-9) & Italy & Spain & Slovenia & Ukraine & Pooled cohort \\
\hline \multicolumn{6}{|l|}{ All causes: } \\
\hline Obs & 547 & 1535 & 569 & 98 & 2749 \\
\hline SMR & 0.90 & 1.14 & 1.18 & 0.90 & 1.08 \\
\hline $95 \% \mathrm{CI}$ & 0.83 to 0.98 & 1.09 to 1.20 & 1.09 to 1.28 & 0.73 to 1.09 & 1.04 to 1.12 \\
\hline \multicolumn{6}{|l|}{ Hypertension (401-405): } \\
\hline Obs & 8 & 31 & 4 & 6 & 49 \\
\hline SMR & 0.58 & 2.78 & 0.50 & 9.38 & 1.46 \\
\hline $95 \% \mathrm{CI}$ & 0.25 to 1.14 & 1.89 to 3.95 & 0.14 to 1.29 & 3.44 to 20.4 & 1.08 to 1.93 \\
\hline \multicolumn{6}{|c|}{ Ischaemic heart disease $(410-414)$ : } \\
\hline Obs & 46 & 103 & 99 & 11 & 259 \\
\hline SMR & 0.45 & 0.69 & 1.66 & 0.44 & 0.77 \\
\hline $95 \% \mathrm{CI}$ & 0.33 to 0.60 & 0.57 to 0.84 & 1.35 to 2.02 & 0.22 to 0.79 & 0.68 to 0.87 \\
\hline \multicolumn{6}{|c|}{ Cerebrovascular diseases (430-438): } \\
\hline Obs & 45 & 179 & 31 & 6 & 261 \\
\hline SMR & 0.61 & 1.17 & 0.71 & 0.53 & 0.93 \\
\hline $95 \% \mathrm{CI}$ & 0.45 to 0.82 & 1.01 to 1.35 & 0.48 to 1.01 & 0.19 to 1.15 & 0.82 to 1.05 \\
\hline \multicolumn{6}{|c|}{ Other diseases of the heart $\left(415-429^{\star}\right)$ : } \\
\hline Obs & 58 & 169 & 44 & 0 & 271 \\
\hline SMR & 1.31 & 1.51 & 1.08 & [2.64] & 1.36 \\
\hline $95 \% \mathrm{CI}$ & 1.00 to 1.70 & 1.29 to 1.76 & 0.78 to 1.45 & 0 to 1.40 & 1.20 to 1.53 \\
\hline \multicolumn{6}{|c|}{ Nephritis, nephrosis (580-589): } \\
\hline Obs & 6 & 36 & 4 & 0 & 46 \\
\hline SMR & 1.11 & 1.69 & 1.60 & {$[0.56]$} & 1.55 \\
\hline $95 \% \mathrm{CI}$ & 0.41 to 2.42 & 1.18 to 2.34 & 0.44 to 4.10 & 0 to 6.59 & 1.13 to 2.06 \\
\hline
\end{tabular}

Expected numbers of deaths are reported in square brackets when observed $=0$.

Obs=number of observed deaths; SMR=standardised mortality ratio.

^Excluding 415.1.

from the Spanish component $(6.4 \%$ in this cohort).

Table 2 shows the results of the analysis of mortality among men from all causes and from cardiovascular and kidney diseases. The overall mortality was increased in Spain and Slovenia, but not in Italy and the Ukraine. Mortality from cardiovascular diseases was not increased overall; and increased mortality from hypertension and from heart diseases other than ischaemic heart disease was found, which was balanced by a reduced mortality from ischaemic heart disease. The main causes of death in the category "other heart diseases" were chronic pulmonary heart disease in Slovenia (24/44 deaths), unspecified myocarditis in Italy (41/58 deaths), and cardiac arrest and unspecified heart disease in Spain (40/169 deaths each). The increase in death from hypertension was present only in Spain and the Ukraine, whereas a decrease in the risk of this disease was found in the other countries. Mortality from ischaemic heart disease was increased in Slovenia but decreased in the other three

Table 3 Mortality from selected causes among men by department of longest employment

\begin{tabular}{|c|c|c|c|}
\hline Cause of death ${ }^{\star}$ & Mine & Mill & Othert \\
\hline \multicolumn{4}{|l|}{ Hypertension: } \\
\hline Obs & 29 & 18 & 2 \\
\hline SMR & 1.92 & 1.07 & 1.30 \\
\hline $95 \% \mathrm{CI}$ & 1.28 to 2.75 & 0.63 to 1.68 & 0.15 to 4.72 \\
\hline \multicolumn{4}{|c|}{ Ischaemic heart disease: } \\
\hline Obs & 168 & 75 & 16 \\
\hline SMR & 1.03 & 0.50 & 0.77 \\
\hline $95 \% \mathrm{CI}$ & 0.88 to 1.20 & 0.39 to 0.62 & 0.44 to 1.24 \\
\hline \multicolumn{4}{|c|}{ Cerebrovascular diseases: } \\
\hline Obs & 154 & 93 & 14 \\
\hline SMR & 1.02 & 0.83 & 0.78 \\
\hline $95 \% \mathrm{CI}$ & 0.86 to 1.19 & 0.67 to 1.02 & 0.42 to 1.30 \\
\hline \multicolumn{4}{|c|}{ Other diseases of the heart: } \\
\hline Obs & 175 & 84 & 12 \\
\hline SMR & 1.48 & 1.24 & 0.91 \\
\hline $95 \% \mathrm{CI}$ & 1.27 to 1.71 & 0.99 to 1.54 & 0.47 to 1.59 \\
\hline \multicolumn{4}{|c|}{ Nephritis, nephrosis: } \\
\hline Obs & 31 & 13 & 2 \\
\hline SMR & 1.71 & 1.39 & 0.87 \\
\hline $95 \% \mathrm{CI}$ & 1.16 to 2.43 & 0.74 to 2.39 & 0.10 to 3.15 \\
\hline
\end{tabular}

Obs=number of observed deaths; SMR=standardised mortality ratio.

* See table 2 for ICD-9 codes.

†Includes filling, byproducts, laboratory, and non-production departments. countries, but an increase in "other" diseases of the heart was found in Italy and Spain. This result might be due to a high proportion of deaths with poor certification of the underlying cause that are coded as heart disease or heart failure. The increased mortality from hypertension and other heart diseases was more pronounced among workers mainly employed in the mines than among those mainly employed in the mills (table 3 ).

When we assessed cardiovascular mortality by indicators of exposure to mercury (table 4), the risk of dying from hypertension increased, although not significantly, with estimated cumulative exposure to mercury, but not with duration of employment. Mortality from ischaemic heart disease and cerebrovascular disease was positively correlated with duration of employment but not with cumulative exposure to mercury. Finally, mortality from other heart disease did not increase with either exposure indicator. An increased mortality from cardiovascular diseases was apparent according to time since first exposure.

We repeated the analysis of ischaemic heart disease and cerebrovascular diseases shown in table 4 separately in the three countries with enough deaths-namely, Italy, Spain, and Slovenia. The results were not fully consistent: in particular, an increased mortality from cerebrovascular disease with increasing duration of employment and estimated exposure was suggested among workers from Spain (relative risk (RR) in the highest category of estimated exposure 1.5 (95\% CI 0.08 to 28$)$ ) and Slovenia (RR 2.4, 95\% CI 0.3 to 17), but not among those from Italy (RR $0.3 ; 95 \%$ CI 0.1 to 1.0 ). Mortality from ischaemic heart disease was non-significantly increased in the Slovenian cohort (RR 2.36, 95\% CI 1.06 to 5.25; RR 2.20, 95\% CI 0.84 to 5.77; and RR $2.61,95 \%$ CI 0.87 to 7.86 (p value 0.3 , test for trend) for the three categories of cumulative exposure $>2000 \mu \mathrm{g} / \mathrm{l} \times$ years shown in table 4 ). 
Table 4 Mortality from cardiovascular and kidney diseases by time since first exposure, duration of employment, and estimated cumulative exposure among men

\begin{tabular}{|c|c|c|c|c|c|}
\hline & \multicolumn{5}{|c|}{ Cause of death ${ }^{*}$} \\
\hline & Hypertension & $\begin{array}{l}\text { Ischaemic } \\
\text { heart disease }\end{array}$ & $\begin{array}{l}\text { Cerebrovascular } \\
\text { diseases }\end{array}$ & $\begin{array}{l}\text { Other diseases } \\
\text { of the heart }\end{array}$ & $\begin{array}{l}\text { Nephritis, } \\
\text { nephrosis }\end{array}$ \\
\hline \multicolumn{6}{|c|}{ Time since first exposure $(\mathrm{y})$ : } \\
\hline Obs & 3 & 29 & 13 & 7 & 7 \\
\hline RR & 1.0 & 1.0 & 1.0 & 1.0 & 1.0 \\
\hline $95 \% \mathrm{CI}$ & - & - & - & - & - \\
\hline \multicolumn{6}{|l|}{ 20-29: } \\
\hline Obs & 8 & 58 & 34 & 43 & 5 \\
\hline $\mathrm{RR}$ & 3.0 & 1.3 & 1.7 & 4.2 & 0.4 \\
\hline $95 \% \mathrm{CI}$ & 0.7 to 13.3 & 0.8 to 2.3 & 0.8 to 3.5 & 1.7 to 10.1 & 0.1 to 1.9 \\
\hline \multicolumn{6}{|l|}{$\geqslant 30$} \\
\hline Obs & 38 & 172 & 214 & 221 & 34 \\
\hline $\mathrm{RR}$ & 5.0 & 1.9 & 2.9 & 6.7 & 0.9 \\
\hline $95 \% \mathrm{CI}$ & 1.0 to 24.4 & 1.1 to 3.5 & 1.3 to 6.1 & 2.7 to 16.5 & 0.2 to 4.4 \\
\hline Trend $\ddagger$ & 0.05 & 0.02 & $<0.01$ & $<0.01$ & 0.7 \\
\hline \multicolumn{6}{|c|}{ Duration of employment $(\mathrm{y})$ : } \\
\hline \multicolumn{6}{|c|}{$1-9: \dagger$} \\
\hline Obs & 7 & 44 & 34 & 36 & 5 \\
\hline RR & 1.0 & 1.0 & 1.0 & 1.0 & 1.0 \\
\hline $95 \% \mathrm{CI}$ & - & - & - & - & - \\
\hline \multicolumn{6}{|l|}{ 10-19: } \\
\hline Obs & 10 & 72 & 37 & 39 & 7 \\
\hline $\mathrm{RR}$ & 0.9 & 1.5 & 1.4 & 1.0 & 3.3 \\
\hline $95 \% \mathrm{CI}$ & 0.3 to 2.9 & 0.9 to 2.5 & 0.8 to 2.5 & 0.6 to 1.7 & 0.8 to 13.0 \\
\hline \multicolumn{6}{|l|}{ 20-29: } \\
\hline Obs & 12 & 95 & 80 & 96 & 13 \\
\hline $\mathrm{RR}$ & 0.5 & 1.7 & 1.4 & 1.0 & 4.7 \\
\hline $95 \% \mathrm{CI}$ & 0.1 to 2.2 & 0.9 to 3.0 & 0.7 to 2.6 & 0.6 to 1.9 & 0.9 to 24.7 \\
\hline \multicolumn{6}{|l|}{$\geqslant 30$} \\
\hline Obs & 20 & 48 & 110 & 100 & 21 \\
\hline $\mathrm{RR}$ & 0.7 & 1.9 & 2.2 & 1.1 & 9.1 \\
\hline $95 \% \mathrm{CI}$ & 0.1 to 3.3 & 0.9 to 4.0 & 1.1 to 4.5 & 0.6 to 2.2 & 1.6 to 52.6 \\
\hline Trend $\ddagger$ & 0.6 & 0.1 & 0.02 & 0.6 & 0.01 \\
\hline \multicolumn{6}{|c|}{ Estimated cumulative exposure ( $\mu \mathrm{g} / 1$ urine-years): } \\
\hline \multicolumn{6}{|c|}{$1-2000: \dagger$} \\
\hline Obs & 5 & 40 & 35 & 38 & 7 \\
\hline $\mathrm{RR}$ & 1.0 & 1.0 & 1.0 & 1.0 & 1.0 \\
\hline $95 \% \mathrm{CI}$ & - & - & - & - & - \\
\hline \multicolumn{6}{|l|}{ 2001-5000: } \\
\hline Obs & 10 & 96 & 44 & 46 & 6 \\
\hline $\mathrm{RR}$ & 1.3 & 1.2 & 0.7 & 0.9 & 0.2 \\
\hline $95 \%$ CI & 0.3 to 4.7 & 0.8 to 2.0 & 0.4 to 1.2 & 0.5 to 1.5 & 0.05 to 1.0 \\
\hline \multicolumn{6}{|l|}{ 5001-7000: } \\
\hline Obs & 11 & 53 & 60 & 66 & 11 \\
\hline $\mathrm{RR}$ & 1.4 & 0.9 & 0.7 & 1.1 & 0.3 \\
\hline $95 \% \mathrm{CI}$ & 0.3 to 6.0 & 0.5 to 1.6 & 0.4 to 1.4 & 0.6 to 2.0 & 0.05 to 1.1 \\
\hline \multicolumn{6}{|l|}{$>7000$} \\
\hline Obs & 23 & 70 & 122 & 121 & 22 \\
\hline $\mathrm{RR}$ & 1.7 & 1.0 & 0.7 & 1.2 & 0.2 \\
\hline $95 \%$ CI & 0.4 to 7.3 & 0.6 to 1.9 & 0.4 to 1.4 & 0.7 to 2.1 & 0.05 to 0.9 \\
\hline Trend $\ddagger$ & 0.5 & 0.8 & 0.6 & 0.3 & 0.2 \\
\hline
\end{tabular}

Obs=number of observed deaths; $\mathrm{RR}=$ relative risk adjusted for age, country, calendar period, time since first employment, and the variables in the table.

* See table 2 for ICD- 9 codes.

†Reference category.

$\neq \mathrm{p}$ Value of test for linear trend.

Mortality from nephritis and nephrosis was increased in Spain and Slovenia (table 2) and among workers mainly employed as miners (table 3). An increased risk was associated with increasing duration of employment but not with time since first exposure; workers with more than $2000 \mu \mathrm{g} / 1 \times$ years cumulative exposure experienced a decreased risk compared with workers with lower exposure, but no trend was detected above that level of exposure (table 4 ).

An increased mortality from pneumoconioses was present in all countries. The SMRs were 54.7 (95\% CI 44.2 to 66.9 ) in Italy, 16.7 (95\% CI 13.0 to 21.1 ) in Spain, and 13.6 (95\% CI 2.81 to 39.9 ) in Slovenia. Two deaths occurred in the Ukraine but the reference rates were not available. This cause of death was negatively associated with duration of employment, and there was a non-significant positive association with estimated cumulative exposure, with the highest risk in the second highest category of exposure (results not shown in detail).

We found an increased mortality from diseases of the skin, and musculoskeletal and connective tissue (ICD-9 680-739, 12 deaths, SMR 1.77, 95\% CI 0.92 to 3.10). The mortality from other causes was unremarkable. In particular, these workers did not experience an increased mortality from accidents.

The analysis of mortality among women from the Ukraine was hampered by small numbers: a total of 19 deaths occurred, yielding an SMR of 0.72 (95\% CI 0.44 to 1.13). Eight deaths were from cardiovascular diseases (SMR $0.71,95 \%$ CI 0.31 to 1.40 ), of which none were from hypertension, one was from ischaemic heart disease, two were from cerebrovascular diseases, and one was from other diseases of the heart (expected 0.3, 4.7, 4.5 , and 0,7 , respectively). One further death was from chronic kidney diseases (0.2 expected).

\section{Discussion}

This study suggests an association between long term exposure to inorganic mercury, as experienced by miners and millers, and increased risk of cardiovascular mortality. The lack of full consistency of the results across countries and the inconsistencies of the results using different exposure indices (table 4) argue against a causal interpretation of our findings. On the other hand, misclassification of exposure and outcome might have contributed to an underestimation of the association between exposure to mercury and mortality from cardiovascular diseases.

Our reconstruction of exposure was based on limited environmental data, mainly from past decades, and it is likely that substantial errors have been introduced in extrapolating across periods and across mines. Given the prospective nature of our study, however, such errors would have resulted in a misclassification of workers (workers at high exposure classified among those at low exposure, and vice versa) that was non-differential with respect to outcome (workers who died from cardiovascular disease had the same probability of being wrongly classified as other workers). In such a situation, the errors in exposure assessment result mainly in underestimation of the association. $^{5}$

Errors in the classification of cause of death as cardiovascular disease would act in the same direction, as long as they would be similar for workers in different exposure groups. In some of the countries, certification of causes of death of cohort members might be of lower quality than in the rest of that country. For example, the area of the Italian mine has the highest proportion of ill defined causes of death of the whole Tuscany region. The high proportion of deaths in the category other diseases of the heart in Spain and Italy also suggests a low quality of certification of causes of death in these two countries. The relatively high number of workers either lost to follow up or 
with unknown cause of death in the Spanish and Ukrainian cohorts adds further uncertainty. These phenomena might contribute to an underestimation of the SMR. However, death certification in Slovenia was of good quality and in internal analyses - such as those shown in table 4 - the bias would more likely be towards the lack of a dose-response relation. For these reasons, we lay more emphasis on results based on internal comparisons - such as those reported in table 4-than on results based on comparisons with an external population-such as those reported in tables 2 and 3.

An additional limitation of our study is the heterogeneity of the methods used in the different countries for the follow up of cohort members and in the timing between period of enrolment of the cohort and period of follow up. In all countries, however, information on cause of death was obtained from death certificates, thus ensuring comparability with the rates used as reference. In Spain and the Ukraine, the follow up was not complete and the loss to follow up was mainly due to migration of workers from the mining area. In particular, many Ukrainian workers might have migrated to Russia after the partition of the former Soviet Union. Most of the workers from Spain lost to follow up were first employed before 1930: when we excluded all Spanish workers employed before that date from the analysis, the results did not change much: the SMR for cardiovascular disease was 1.07 (95\% CI 0.85 to 1.34 ). Furthermore, differences in cardiovascular mortality between countries might reflect differences in survival rather than incidence.

The lack of availability of reference mortalities for part of the study period in Slovenia and the Ukraine is a further limitation of our study. For the Ukrainian cohort, the period covered by the extrapolation contributed, in men, only $17 \%$ of expected deaths; this figure is $54 \%$ for the Slovenian cohort. This problem, however, only affects the comparison with an external reference population but does not invalidate the analyses based on internal comparisonssuch as those shown in table 4 .

If the association between employment in the mines under study and increased risk of some cardiovascular diseases is real, it might be due to exposure to inorganic mercury, to other occupational exposures, or to nonoccupational confounders.

Miners from Slovenia and Spain experienced exposure to crystalline silica; despite the limited measurements available, the increased mortality from pneumoconiosis was clearly confirmed. It is of interest to note that the increased risk of death from pneumoconiosis was present also among mill workers from Italy, suggesting substantial turnover between the mine and the refining plant.

Given the nephrotoxicity of silica, ${ }^{6}$ the increase in mortality from hypertension found in this study can be attributed to concomitant exposure to silica. The other agents present in the working environment, and particularly radon and its decay products, are not known to increase cardiovascular risk. An increased consumption of tobacco among miners compared with the general population of the four countries under study might also increase cardiovascular mortality. Apart from evidence of high rates of smoking among miners from Slovenia (prevalence of smokers around $70 \%$, with average consumption of more than 20 cigarettes a day), we have no direct information on the pattern of smoking of miners from the other countries. There are, however, several indirect arguments against the hypothesis of a confounding effect of tobacco. Mortality from diseases strongly associated with tobacco smoking - such as bronchitis, emphysema, and asthma - was not increased and mortality from lung cancer showed only a small increase (SMR 1.19). Furthermore, confounding by tobacco smoking is unlikely to explain the trend in cardiovascular risk with duration of employment. Finally, a higher risk for ischaemic heart disease than for other cardiovascular diseases would be expected, although the results suggested the opposite pattern. Other potential non-occupational confounders of our results on cardiovascular diseases include dietary habits and psychogenic stress.

It is plausible, therefore, that exposure to mercury might have contributed, at least in part, to the results on cardiovascular mortality.

If the hypothesis that an effect of exposure to inorganic mercury on the cardiovascular system is compatible with our results, what could be the mechanism? Hypertension after nephrotoxicity has been found in experimental animals, ${ }^{7}$ and might be an explanation. ${ }^{1}$ On the other hand, the facts that mortality from hypertension was increased and that there was a stronger suggestion of a dose-response relation between estimated cumulative exposure and this disease compared with other cardiovascular diseases supports the hypothesis of kidney mediated hypertension as an effect of exposure to mercury on the cardiovascular system. It is of interest to note that another heavy metal, lead, is known to cause nephrotoxicity and renal hypertension. ${ }^{8}$

No data are available in the scientific literature on possible direct effects of inorganic mercury on the heart or the blood vessels. In a Swedish study of chloralkali workers exposed to inorganic mercury, an excess mortality from cardiovascular diseases was suggested, ${ }^{9}$ which was not confirmed in a similar study from Norway, ${ }^{10}$ nor in an American study of nuclear weapon workers exposed to mercury vapour ${ }^{11}$ and a small Italian study of fur hat workers compensated for mercury intoxication. ${ }^{12}$ In a cross sectional study of American chloralkali workers the prevalence of hypertension was not increased, ${ }^{13}$ whereas in an unpublished cross sectional study of miners from Almaden, Spain, the prevalence of hypertension was 33\% among drillers and $24 \%$ among carpenters of similar age (quoted by Barregard et al). ${ }^{\circ}$

It is known that mercury promotes the formation of free radicals ${ }^{14}$ and the peroxidative degradation of lipids ${ }^{15}{ }^{16}$; it reduces the antioxidative effect of selenium ${ }^{17}$ and the activity of 
superoxide dismutase and catalase. ${ }^{18} 19$ Mercury can therefore contribute to the process of atherosclerosis which is a key event in the pathogenesis of ischaemic heart disease. In a study of retired miners from the Slovenian mine, high concentrations of mercury and selenium were found in different body tissues several years after the end of exposure, and a roughly 1:1 molar ratio between the two elements. ${ }^{20}$ Similar findings have been reported on retired dentists from Sweden. ${ }^{21}$ The accumulation of mercury can reduce the bioavailability of selenium, and can be one of the mechanisms through which mercury promotes lipid peroxidation. This should be seen in the light of a likely high intake of saturated animal fat in miners from Slovenia and possibly the other countries under study.

Despite the limitations in assessment of exposure and outcome, this study suggests an association between employment in mercury mining and refining and mortality from cardiovascular diseases. Although exposure to crystalline silica occurred among these workers, it is unlikely that this agent explains the pattern in mortality from cardiovascular diseases. Exposure to inorganic mercury remains a plausible explanation of our findings. This investigation therefore adds support to the efforts to reduce occupational and environmental exposure to inorganic mercury. Further investigations of the possible effects of inorganic mercury on the cardiovascular system are warranted.

This study was partially supported by the European Commission, BIOMED contracts No BMH1-CT92-1110 and BMH4 CT95-1100, and by the Spanish Fondo de Investigacion Sanitaria, contract No 96/0942.

1 International Programme on Chemical Safety. Mercury, inorganic. Geneva: WHO, 1991. (Environmental Health Criteria No 118 .)

2 Boffetta P, Garcia-Gómez M, Pompe-Kirn V, et al. Cancer occurrence among European mercury miners. Cancer Causes Control 1998;9:591-9.
3 Kobal A, Dizdarevic T. The health safety programme for workers exposed to elemental mercury at the mercury mine in Idrija. Proceedings of the Conference on Mercury as a Global Pollutant. Hamburg: 4-8 August 1996.

4 Breslow NE, Day NE. Statistical methods in cancer research. Vol II. The design and analysis of cohort studies. Lyon: International Agency for Research on Cancer, 1987. (IARC Scic Publ No 82.)

5 Rothman KJ, Greenland S, eds, Modern epidemiology, 2nd ed. Philadelphia, PA: Lippincott-Raven, 1998.

6 International Agency for Research on Cancer. Silica. In: IARC Monographs on the evaluation of carcinogenic risks to humans. Vol 68. Silica, some silicates, coal dust and para-aramid fibrils. Lyon, IARC, 1997:183.

7 Carmignani M, Boscolo P. Cardiovascular homeostasis in rats chronically exposed to mercuric chloride. Arch Toxicol Suppl 1984;7:383-8.

8 Loghman-Adham M. Renal effects of environmental and occupational lead exposure. Environ Health Perspect 1997; 105:928-39.

9 Barregard L, Sallsten G, Jarvholm B. Mortality and cancer incidence in chloralkali workers exposed to inorganic mercury. Br F Ind Med 1990;47:99-104.

10 Ellingsen DG, Andersen A, Nordhagen HP, et al. Incidence of cancer and mortality among workers exposed to mercury vapour in the Norwegian chloralkali industry. $\mathrm{Br} F$ Ind $\mathrm{Med}$ 1993; 50:875-80.

11 Cragle DL, Hollis DR, Qualters JR, et al. A mortality study of men exposed to elemental mercury. F Occup Med 1984; 26:817-21.

12 Merler E, Boffetta P, Masala G, et al. A cohort study of workers compensated for mercury intoxication following employment in the fur hat industry. F Occup Med 1994;36: 1260-4.

13 Smith RG, Vorwald AJ, Patil LS, et al. Effects of exposure to mercury in the manufacture of chlorine. Am Ind Hyg Assoc f 1970;31:687-700.

14 Ganther HE. Interactions of vitamin $\mathrm{E}$ and selenium with mercury and silver. Ann N Y Acad Sci 1980;355:212-26.

15 Halliwell B, Gutteridge JMC. Free radicals in biology and medicine, 2nd ed. Oxford: Clarendon Press, 1989.

16 Sunderman FW Jr. Metals and lipid peroxidation. Acta Pharmacol Toxicol (Copenh) 1986;59(suppl 7):248-55.

17 Ganther HE, Goudie C, Sunde ML, et al. Selenium: relation to decreased toxicity of methylmercury added to diets containing tuna. Science 1972;175:1122-4.

18 Benov LC, Benchev IC, Monovich OH. Thiol antidotes effect on lipid peroxidation in mercury-poisoned rats. Chem Biol Interact 1990;76:321-32.

19 Bulat P, Dujic I, Potkonjak B, et al. Activity of glutathione peroxidase and superoxide dismutase in workers occupationally exposed to mercury. Int Arch Occup Environ Health 1998;71:S37-9.

20 Kosta L, Byrne AR, Zelenko V. Correlation between selenium and mercury in man following exposure to inorganic mercury. Nature 1975;254:238-9.

21 Nylander M, Weiner J. Mercury and selenium concentrations and their interrelations in organs from dental staff and the general population. Br F Ind Med 1991;48:729-34. 